\title{
0 trabalho com a oralidade nas aulas de inglês em tempos de pandemia
}

\section{Teaching speaking in the English classes during the pandemic context}

\author{
Patrícia Cardoso Batista1 \\ Josimayre Novelli ${ }^{2}$
}

\begin{abstract}
Resumo
Neste texto relata-se as experiências vividas durante o Estágio Curricular Supervisionado de Língua Inglesa (LI) no contexto da pandemia, enfocando o trabalho com a oralidade. 0 desenvolvimento dessa habilidade linguístico-comunicativa (speaking) é muito importante, uma vez ser necessária a comunicação em uma língua estrangeira (LE). Ressalta-se que o estágio foi realizado em um $8 .^{\circ}$ ano, do Ensino Fundamental, em uma escola da rede pública estadual de Londrina-PR. Como resultados, observou-se a dificuldade de trabalhar com 0 ensino da oralidade nas aulas de LI durante a pandemia, pois os alunos apresentam inibição em falar em outro idioma, bem como é uma das habilidades que ocupa menos espaço no currículo escolar ao se considerar os objetivos do ensino de uma LE na educação básica (PARANÁ, 2008; 2018). Logo, percebe-se a necessidade de abordar a oralidade a fim de que haja mudanças na prática escolar para que os estudantes aprendam comandos e gêneros da esfera da oralidade com o intuito de promover uma comunicação mínima durante a escolarização.
\end{abstract}

Palavras-chave: Estágio Supervisionado. Língua Inglesa. Oralidade. Escola Pública.

\begin{abstract}
The text reports the experiences lived during the Supervised Curricular Internship of the English Language in the context of the pandemic, focusing on the work with speaking. The development of this linguistic-communicative skill (speaking) is very important, since communication in a foreign language is necessary. It is noteworthy that the internship was carried out in the 8th year of Elementary School, in a state public school in Londrina-PR. As a result, the difficulty of working with the teaching of speaking in English classes during the pandemic was observed, as students are inhibited in speaking in another language, as well as being one of the skills that occupies less space in the school curriculum when considering the objectives of teaching a foreign language in basic education (PARANÁ, 2008; 2018). Therefore, there is a need to address speaking so that there are changes in school practice so that students learn commands and genres in the sphere of orality in order to promote minimal communication during schooling.
\end{abstract}

Keywords: Supervised Internship. English language. Speaking. Public school.

\section{Introdução}

No presente texto, relata-se as atividades desenvolvidas durante o Estágio Curricular Supervisionado V - Língua Inglesa (LI) (Ensino Fundamental), componente obrigatório do curso de licenciatura em Letras-EaD (Português e Inglês), que foi desenvolvido em um 8. ${ }^{\circ}$ ano, no ano de 2021. Durante o estágio foi realizada a observação das aulas por meio da plataforma de conferências on-line Google Meet, com o intuito de se refletir sobre os aspectos do processo de ensino e aprendizagem de

\footnotetext{
${ }^{1}$ Doutoranda pelo Programa de Pós-Graduação em Estudos da Linguagem da Universidade Estadual de Londrina - UEL. Londrina, Paraná, Brasil. Orcid: https://orcid.org/0000-0002-3096-6178. E-mail: patricia.cardoso@uel.br

${ }^{2}$ Professora de Língua Inglesa do Departamento de Letras Modernas da Universidade Estadual de Maringá - UEM. Maringá, Paraná, Brasil. Orcid: https://orcid.org/0000-0001-5137-553X. E-mail: inovelli@uem.br
} 
inglês, bem como foram elaborados planos de aula para a regência, a qual ocorreu por meio da gravação de videoaulas. Logo, essas atividades propiciaram vivenciar e conhecer como a Ll é abordada na rede pública de educação, especialmente no que se refere ao trabalho com a oralidade, levando a reflexão sobre a importância e complexidade de desenvolver essa habilidade ainda durante o período de escolarização.

Diante disso, ressalta-se que, devido à pandemia causada pela Covid-19, todas as atividades de estágio aconteceram de forma remota, pois a publicação da PORTARIA N. ${ }^{\circ}$ 544, DE 16 DE JUNHO DE 2020 (MEC) autorizou os cursos de licenciatura a realizarem as atividades de estágio por meios digitais neste momento, pois ocorriam presencialmente, inclusive em cursos EaD. Logo passou-se a observar, elaborar e ministrar as aulas na modalidade remota.

Dessa maneira, vale enfatizar que o Ensino Remoto Emergencial (ERE) é uma opção utilizada para "circunstâncias de pressão geradas pela crise que envolve o uso de soluções totalmente remotas para instrução ou educação que seria presencial ou para cursos mistos ou híbridos que voltarão ao seu formato de origem após a crise" (VELOSO; WALESCO, 2020, p. 37). Isto é, uma solução temporária apenas para atender as demandas causadas pela pandemia.

Ao atuar no contexto da pandemia, muitas dificuldades surgiram, não só para os estagiários, mas para os docentes e alunos da Educação Básica que também tiveram que se reinventar para ensinar e aprender inglês em uma modalidade diversa. A respeito do ensino da $L I$ na rede regular de ensino, chama-se a atenção às dificuldades de trabalhar com o desenvolvimento da oralidade, o que é um assunto já bastante discutido na área, mas que está longe de ser resolvido na prática escolar.

0 desenvolvimento da oralidade (speaking) é muito importante para aqueles que estão aprendendo uma segunda língua e querem se comunicar com fluência. Entretanto, segundo Rio e Nicolaides (2019), muitos estudos demostram o desafio de trabalhar com a oralidade nas escolas públicas brasileiras, o que tem diversas motivações, como a sobrecarga de trabalho dos docentes, desmotivação para o ensino de uma LE, salas de aulas lotadas, formação docente lacunar, ou mesmo resistência dos alunos, pois, por vezes, sentem-se apreensivos ou com vergonha de falar na língua-alvo. Logo, uma dificuldade a mais foi acrescentada no período pandêmico, a distância entre alunos e professores, bem como a possibilidade de manter câmeras e áudios desativados durante as aulas síncronas realizadas por plataformas digitais.

Neste sentido, apesar dos avanços das discussões sobre a importância de trabalhar com as quatro habilidades linguístico-comunicativas: leitura, produção e compreensão escrita, produção e compreensão oral, conforme orientado em documentos oficiais, como Orientações Curriculares para 0 
Ensino Médio (OCEM) (BRASIL, 2006) e Base Nacional Comum Curricular (BNCC) (BRASIL, 2017), na prática escolar observada neste estágio, verificou-se que a oralidade é a menos enfatizada. Logo, questiona-se: Como favorecer o desenvolvimento da oralidade nas aulas de LI na rede pública estadual?

A esse respeito, Rio e Nicolaides (2019) defendem que o uso das tecnologias digitais pode auxiliar alunos e professores na aprendizagem da LI, especialmente agora em que as interações estão ocorrendo, majoritariamente, por meio de ferramentas tecnológicas devido à pandemia. Nesta perspectiva, Rio e Nicolaides (2019, p. 41) argumentam que as tecnologias digitais, se "[...] empregadas de maneira crítica e sensivelmente contextualizada [...] podem trazer ganhos imediatos e longínquos na aprendizagem de língua inglesa, especialmente no tocante ao ensino e aprendizagem da oralidade no idioma [...]". Logo, fica evidente que é possível desenvolver a oralidade nas aulas de língua inglesa, mas para isso essa habilidade deve ser mais priorizada no ensino.

Nesta esteira, neste texto, enfoca-se, por meio de teorias da área e vivências propiciadas pelo estágio, o trabalho com a oralidade em tempos de pandemia, bem como se pondera a complexidade e importância de desenvolver essa habilidade na educação básica.

\section{Fundamentação teórica}

Nesta seção, discorre-se sobre a complexidade de desenvolver a oralidade em uma LE, bem como se problematiza a questão do seu ensino na rede regular de ensino. Na sequência, aborda-se como os documentos oficiais orientam o trabalho com essa habilidade na Educação Básica. Por último, enfoca-se nas dificuldades enfrentadas para desenvolvê-la e sugere-se algumas estratégias para colocála mais em pauta na sala de aula.

\subsection{Oralidade e a complexidade do seu desenvolvimento}

A oralidade, ao contrário do que muitos pensam, é uma habilidade bem complexa de se desenvolver, pois, segundo Rio e Nicolaides (2019, p. 40), envolve "[...] uso de diversas habilidades, como as interacionais, cognitivas, sociais, linguísticas, fisiológicas, entre outras correlatas".

Para interagir com 0 outro, usamos habilidades interacionais que envolvem "[...] 0 manuseamento dos turnos da conversa, respeito e polidez ao ouvir e ao falar com o interlocutor, assim como também saber utilizar sentenças da melhor maneira a fim de se alcançar o resultado esperado" (RIO; NICOLAIDES, 2019, p. 40). 
Ademais, o desenvolvimento da oralidade abrange também habilidades cognitivas, que estão relacionadas à "[...] estruturação dos lexemas dentro das diferentes sentenças" (RIO; NICOLAIDES, 2019, p. 40). A esse respeito, é importante considerar que estruturar as sentenças na LI, muitas vezes, difere do português, por exemplo, os adjetivos são ordenados de formas diversas nas duas línguas, ou mesmo a forma de formular perguntas, pois exige o uso de verbos auxiliares ou mesmo a inversão da ordem das palavras.

Quanto às habilidades sociais, estas estão ligadas à "[...] compreensão de com quem os diferentes sujeitos estão interagindo, ajustando suas produções linguísticas aos diferentes papéis desempenhados em instâncias dissimilares" (RIO; NICOLAIDES, 2019, p. 40). Ou seja, conversar com um amigo difere de conversar com um professor.

No que se referem às habilidades linguísticas, relacionam-se ao entendimento da LE, 0 "uso/adaptação de diferentes sentenças, estilos/figuras de linguagens usadas nos variados contextos (linguagem formal ou informal, metafórica ou literal), uso de variados sentidos construídos dentro do sistema linguístico empregado" (RIO; NICOLAIDES, 2019, p. 40).

Por fim, as habilidades fisiológicas implicam "[...] a gesticulação apropriada das palavras (em nível fonológico e fonético), bem como a utilização corporal (confirmação de entendimento de uma informação ao movimentar a cabeça, uso de gestos, mímicas), ajudando, grupalmente, na constituição de sentido" (RIO; NICOLAIDES, 2019, p. 40). Diante disso, fica claro a importância de se desenvolver a oralidade em sala de aula para que 0 aluno tenha a oportunidade de aprimorar todas essas habilidades.

Em relação à realidade do ensino da LI nas escolas públicas brasileiras, Corrêa (2017) argumenta que o senso comum acredita que o inglês ofertado pela escola não garante que o sujeito se comunique na língua, mesmo tendo estudado durante anos da escolarização. Os motivos para isso são muitos, conforme já enfatizado, pois falta investimento governamental, professores despreparados, infraestrutura precária, indisciplina dos estudantes, etc. Nesse sentido, ela reforça que "O professor da disciplina, em geral, limita-se a trabalhar, em sala de aula, o ensino da escrita, questões gramaticais, de interpretação de texto e vocabulário, desprivilegiando a oralidade no idioma" (CORREAA, 2017, p. 298). Entretanto, a autora alerta para os malefícios desse discurso do fracasso que coloca como impossível aprender uma língua adicional em escolas regulares.

Segundo Corrêa (2017), estudos da área mostram que muitas pessoas acreditam que só se aprende inglês estudando no exterior ou em escolas de idiomas, não em escolas públicas. Esse discurso leva à exclusão daqueles que só terão acesso a uma língua adicional por meio da escola, bem como desmotiva professores e alunos. Diante disso, Corrêa (2017, p. 311) defende que "[...] um maior incentivo 
ao uso da língua em sala poderia ser uma maneira para contribuir para um processo de ensinoaprendizagem mais motivador e construtivo". Logo, percebemos a necessidade de 0 inglês ser mais utilizado nas aulas destinadas ao ensino de LE, estimulando os discentes a falarem mais na língua-alvo.

2.20 ensino de inglês nos documentos oficiais: oralidade em foco

Os documentos oficiais que orientam o ensino da LI no Brasil sofreram alterações ao longo do tempo, especialmente no que se refere às habilidades (leitura, escrita, oralidade e compreensão auditiva) enfocadas.

A esse respeito, ressalta-se que os Parâmetros Curriculares Nacionais (PCN) (BRASIL, 1998) priorizam o desenvolvimento da leitura por ser cobrada em vestibulares e testes, o que difere bastante do objetivo das escolas de idiomas e particulares, que priorizam o desenvolvimento da fala (speaking), por exemplo. Logo, isso reforça o pressuposto de que não é possível aprender a falar inglês na escola. As OCEM (BRASIL, 2006), por sua vez, enfatizam a compreensão e produção de textos orais e escritos, todavia não é isso que se observa na prática em salas de aula. Já as Diretrizes Curriculares Estaduais (DCE) (PARANÁ, 2008) priorizam as habilidades comunicativas, como falar e escrever. Por fim, a BNCC (BRASIL, 2017), documento mais recente, contempla o desenvolvimento da oralidade, leitura, escrita, conhecimentos linguísticos e da dimensão intercultural.

A BNCC, publicada em 2017, também adota a posição do inglês como língua franca (ILF), dado que 0 inglês é falado no mundo todo, não só nos países que o têm como língua oficial. Isto é, o inglês "correto" não é somente aquele falado por estadunidenses e britânicos. Logo, é um ponto importante para ser considerado no trabalho do professor com a língua inglesa, pois implica 0 acolhimento de diferentes formas de se expressar na LI. Diante disso, o aspecto comunicativo da língua é ressaltado pelo documento, uma vez que o inglês pode ser utilizado por falantes de diversas línguas para se comunicar (BRASIL, 2017).

Esse entendimento favorece uma educação linguística voltada para a interculturalidade, isto é, para o reconhecimento das (e o respeito às) diferenças, e para a compreensão de como elas são produzidas nas diversas práticas sociais de linguagem, 0 que favorece a reflexão crítica sobre diferentes modos de ver e de analisar o mundo, o(s) outro(s) e a si mesmo (BRASIL, 2017, p. 242).

Assim sendo, reconhece-se que o ILF tem essência multilíngue, pois pode ser usado em situações interculturais em que falantes de diferentes línguas maternas e culturas utilizam o inglês para 
se comunicar. Em vista disso, implica o acolhimento de diferentes formas de se expressar na LI, deslocando-se daquele modelo ideal de falante (GIMENEZ et al., 2015). Diante disso, observa-se que olhar para o inglês como língua franca desmistifica-se a crença de que o bom inglês é apenas aquele falado por nativos, uma vez que o importante é ser compreendido e se comunicar. Nesse sentido, considera-se essa uma perspectiva interessante para o ensino, pois resulta no estabelecimento de metas mais realistas, enfocando o uso real da língua e na desmistificação de preconceitos linguísticos, tendo em vista que o sotaque é considerado como parte da identidade do educando e enfatiza-se o respeito às diferenças.

No que diz respeito à oralidade, enfoque deste texto, a BNCC (BRASIL, 2017) diz que:

"[...] envolve as práticas de linguagem em situações de uso oral da língua inglesa, com foco na compreensão (ou escuta) e na produção oral (ou fala), articuladas pela negociação na construção de significados partilhados pelos interlocutores e/ou participantes envolvidos, com ou sem contato face a face [...]" (BRASIL, 2017, p. 243).

O documento destaca algumas práticas de linguagem que se dão por meio de gêneros orais (entrevistas, debates, etc.), e que envolvem "[...] Itens lexicais e estruturas linguísticas utilizados, pronúncia, entonação e ritmo empregados" (BRASIL, 2017, p. 243). Assim, comunicar-se com o outro por meio da LI é uma atividade complexa, por isso merece o seu lugar em nossas aulas.

Além disso, a oralidade leva ao desenvolvimento de "[...] comportamentos e atitudes - como arriscar-se e se fazer compreender, dar voz e vez ao outro, entender e acolher a perspectiva do outro, superar mal-entendidos e lidar com a insegurança, por exemplo" (BRASIL, 2017, p. 243). Nesse sentido, espera-se que o aluno consiga interagir e usar a língua-alvo, bem como consiga compreender e produzir textos orais com autonomia.

\subsection{Dificuldades e estratégias para o trabalho com a oralidade na língua inglesa}

Trabalhar com a oralidade nas aulas de LE não é tarefa nada fácil, pois alguns obstáculos podem surgir em sala de aula. A esse respeito, Ur (1999 apud ALVES, 2015) expõe algumas das dificuldades que podem surgir, como: inibição, dado que o aluno pode não se sentir confortável em falar em outra língua para todos da sala, seja por medo de errar ou por ser tímido; quando não há nada a dizer, ou seja, não ter familiaridade com o tema proposto e o que falar sobre ele; baixa participação devido ao pouco tempo para realização das atividades em sala, ou nem todos conseguem se expressar na língua-alvo; uso do português por ter mais segurança, etc. 
Diante disso, observa-se que o professor deverá recorrer a diferentes estratégias para planejar atividades que visem ao desenvolvimento da oralidade e superar as possíveis adversidades. Em vista disso, Harmer (2001 apud ALVES, 2015) elenca alguns tipos de atividades que podem ser usadas durante as aulas, tais como: utilização de roteiros; jogos comunicativos; discussões; palestras planejadas; questionários; simulação e dramatização. Vale ressaltar que ao escolher uma delas é importante estar ciente que acontecem sempre imprevistos, e que em alguns contextos será necessário adaptar a atividade, considerando a especificidade do público-alvo, a do próprio contexto de ensino, bem como os objetivos a serem ensinados.

Em vista disso, faz-se necessário trabalhar com a oralidade visando o desenvolvimento da fala. Para tanto, é importante criar situações reais em que os alunos precisam utilizar a língua. Assim sendo, em sala de aula, é salutar promover situações comunicativas que privilegiam a interação e o uso do inglês em um contexto social.

Diante de um contexto pandêmico, cabe aos professores pensar em estratégias para 0 desenvolvimento da fala. Para tanto, podem usar vários recursos tecnológicos que permitem um trabalho melhor com a oralidade, uma vez que há várias opções. Por exemplo, Maria e Vieira (2020) sugerem o uso do Google Tradutor, que pode ser usado como uma ferramenta para a prática da produção oral na LI, dado que basta acessar a ferramenta digital pelo computador ou celular e usar o microfone para praticar a fala. Outra opção é marcar conversas em grupos criados com o aplicativo WhatsApp e também usar a divisão de grupos em salas de aulas virtuais, as quais permitem o desenvolvimento de atividades voltadas para a comunicação/oralidade mais efetiva, sendo supervisionada pelo professor. Portanto, percebe-se a necessidade de o docente de $\mathrm{LI}$ recorrer a outros recursos para promover 0 desenvolvimento da oralidade neste momento ${ }^{3}$.

\section{Metodologia}

Nesta seção, abordam-se as atividades desenvolvidas no referido estágio, realizado em um $8 .^{\circ}$ ano, com 35 alunos, no Ensino Fundamental, no $1 .{ }^{\circ}$ semestre de 2021, em uma escola da rede pública estadual da cidade de Londrina, no estado do Paraná. A experiência do estágio ocorreu em três modalidades: observação das aulas, planejamento das aulas e regência.

As observações das cinco aulas foram realizadas durante os meses de abril, maio e junho. É importante salientar que todas as observações foram feitas por meio da plataforma Google Meet, e

\footnotetext{
${ }^{3}$ Para informações a respeito das diversas ferramentas digitais e tecnológicas utilizadas no ensino de línguas, acesse: https://www.dropbox.com/s/5soe0qiny6953me/MAO_NA_MASSA.pdf?dl=0\%20 (NASCIMENTO et al., 2019).
} 
aconteceram de maneira síncrona. Nesta esteira, enfatiza-se que a professora designada como supervisora do estágio na referida escola foi muito receptiva e manteve contado contínuo pelo WhatsApp com a estagiária, mostrando-se disposta a ajudar e aberta a discussões.

$\mathrm{Na}$ primeira aula (26/04), ela apresentou a aluna-professora aos alunos e disse que acompanharia as aulas. Essa apresentação foi feita em LI, o que causou estranhamento nos alunos. Nesta aula, a professora da turma retomou um texto que havia começado a trabalhar na aula anterior. Logo, ela compartilhou a sua tela do computador com o texto e atividades. Os alunos copiaram as atividades e, na sequência, corrigiu com eles. No final da aula, ela fez a chamada pelo sistema da Secretaria da Educação do Estado do Paraná.

Na segunda aula (27/04), a docente deixou uma música em inglês do YouTube de fundo até que todos os alunos entrassem na sala do Google Meet. Neste dia, ela trabalhou com Simple Present e a conjugação dos verbos diante de she, he e it. Alguns alunos ainda estavam com dúvida sobre o uso do presente simples e ela teve que explicar o conteúdo novamente, pois a avaliação da disciplina estava próxima. Além disso, a professora retomou o uso dos verbos auxiliares do e does em perguntas.

Na terceira aula (03/05), a professora abordou o conteúdo Daily Routine. Para tanto, ela iniciou a aula indagando, em português, o que os alunos faziam no seu dia a dia, e alguns deles responderam, mas também em português. Foi possível perceber que nem a professora, nem os alunos se arriscavam a fazer interações espontâneas na língua-alvo. Na sequência, ela apresentou alguns verbos do inglês utilizados para descrever a rotina e passou um vídeo do YouTube com a rotina de Mariana. Logo, os alunos tiveram que falar sobre o que entenderam, mas também em português.

Na quarta aula (04/05), a docente levou o texto Shophies's daily routine para interpretação na LI. Uma aluna se voluntariou a ler o texto em voz alta para a turma. Depois, os estudantes identificaram as palavras que sabiam, mas apresentaram um vocabulário bem precário no idioma. Na sequência, eles copiaram as questões no caderno e responderam às perguntas. A professora mandou o texto no grupo da sala para facilitar a localização das respostas.

Na quinta aula observada (17/05), a docente fez a correção da atividade do texto Shophies's daily routine. Ela focou na conjugação verbal dos verbos do presente simples e o acréscimo do -s nos verbos conjugados na terceira pessoa do singular. $O$ inglês era usado apenas para a leitura dos exercícios, pois toda a aula foi ministrada em português. Nesta aula, ela também comentou sobre 0 resultado das avaliações.

Portanto, nas aulas observadas, percebeu-se um ensino tradicional da LI, pois teve como foco 0 ensino de gramática, de forma estrutural, que seria cobrada na avaliação. Nesse sentido, houve a 
predominância do método da Gramática e da Tradução (Grammar-Translation Method), sendo fundamentado na teoria da gramática universal e pauta-se na tradução de textos e frases (BORGHI, 2013). Logo, a professora fala na língua materna, enfocando as regras gramaticais e na lista de palavras descontextualizadas. Então, o foco das aulas observadas foi apenas no desenvolvimento da escrita e leitura, e não da produção oral. Logo, em nenhuma das aulas observadas houve 0 trabalho com a oralidade, o que é necessário para o aluno poder falar na língua-alvo de forma eficaz. Além disso, constatou-se que a professora utilizava o inglês apenas durante a leitura dos comandos das atividades, e a maioria das aulas e interações aconteciam em português.

Para o planejamento da regência, a professora da turma indicou o conteúdo a ser ministrado para os alunos. Neste sentido, elaboraram-se cinco planos de aula com temas variados, contemplando 10 horas-aula para o ensino de LI no $8 .^{\circ}$ ano, conforme o quadro apresentado abaixo:

\begin{tabular}{|c|c|c|c|c|}
\hline \multicolumn{5}{|c|}{ Conteúdo } \\
\hline $\begin{array}{c}\text { Word variations: American, } \\
\text { British, Australian, } \\
\text { Canadian... }\end{array}$ & Different accents. & $\begin{array}{l}\text { Clothes and } \\
\text { colors. }\end{array}$ & Shopping clothes. & $\begin{array}{c}\text { Reading and } \\
\text { comprehension of text. }\end{array}$ \\
\hline \multicolumn{5}{|c|}{ Objetivo geral } \\
\hline $\begin{array}{l}\text { Proporcionar aos alunos } \\
\text { conhecer, de forma crítica, } \\
\text { as variações na escrita do } \\
\text { inglês. }\end{array}$ & $\begin{array}{l}\text { Promover aos } \\
\text { alunos uma } \\
\text { reflexão sobre os } \\
\text { diferentes sotaques } \\
\text { da língua inglesa. }\end{array}$ & $\begin{array}{l}\text { Apresentar aos } \\
\text { alunos o } \\
\text { vocabulário } \\
\text { relacionado a } \\
\text { cores e peças de } \\
\text { roupas. }\end{array}$ & $\begin{array}{c}\text { Desenvolver } \\
\text { atividades que } \\
\text { possibilitem aos } \\
\text { alunos a } \\
\text { compreensão, } \\
\text { interpretação e } \\
\text { discussão crítica do } \\
\text { assunto. }\end{array}$ & $\begin{array}{l}\text { Promover atividades de } \\
\text { leitura e interpretação } \\
\text { de textos que } \\
\text { possibilitem o } \\
\text { desenvolvimento da } \\
\text { criticidade nos alunos. }\end{array}$ \\
\hline \multicolumn{5}{|c|}{ Habilidades } \\
\hline $\begin{array}{c}\text { Compreensão e produção } \\
\text { oral } \\
\text { Escrita }\end{array}$ & $\begin{array}{l}\text { Compreensão e } \\
\text { produção oral } \\
\text { Leitura }\end{array}$ & $\begin{array}{l}\text { Compreensão e } \\
\text { produção oral }\end{array}$ & $\begin{array}{l}\text { Compreensão e } \\
\text { produção oral } \\
\text { Gramática }\end{array}$ & $\begin{array}{c}\text { Leitura } \\
\text { Produção oral }\end{array}$ \\
\hline
\end{tabular}

Quadro 1. Resumo dos planos de aula

Fonte: As autoras.

Em relação à regência realizada no estágio, esta foi planejada e sempre contava com três momentos: uma apresentação para introduzir o conteúdo e ativar os conhecimentos prévios dos alunos; o momento da prática destinado à realização de atividades; último momento para retomar o que foi aprendido na aula. Devido à pandemia, as aulas tiveram que ser gravadas em vídeo, ou seja, aconteceram de forma assíncrona. Para tanto, utilizou-se os recursos do Google Meet, como o compartilhamento de slides a fim de valorizar o uso de recursos visuais para facilitar a compreensão, uma vez que a língua inglesa foi usada na maior parte da aula. Desse modo, como método de ensino, priorizou-se o comunicativo (Communicative Language Teaching Method) porque enfoca no trabalho 
com as quatro habilidades (writing, reading, speaking, listening), sendo variadas e/ou combinadas nos planos de aula elaborados, conforme discriminado no Quadro 1. Vale ressaltar que diante da pouca ênfase da oralidade nas aulas de inglês, optou-se por trabalhar com essa habilidade em algum momento das aulas.

Vale ressaltar que visando atender às exigências da disciplina do Estágio Supervisionado, apenas duas aulas foram eleitas para a gravação em vídeo, bem como para a disponibilização aos alunos como material complementar pela professora supervisora no Classroom. Por isso, neste texto, descrevemos somente duas videoaulas.

Na primeira aula gravada, trabalhou-se com o vocabulário relacionado a cores e peças de roupas. Para tanto, fez-se perguntas para resgatar os conhecimentos prévios dos estudantes. $\mathrm{Na}$ sequência, passou-se um víde $0^{4}$ sobre a origem do jeans para os alunos e responderam algumas perguntas visando a construção de sentidos. Depois apresentou-se o vocabulário sobre roupas e cores, incentivando a prática da pronúncia e realização de exercícios sobre o conteúdo. Para finalizar a aula e revisar o que foi estudado, propôs-se um jogo, que consistia em um vídeo ${ }^{5}$ para os alunos adivinharem o nome das roupas desenhadas em até 5 segundos.

$\mathrm{Na}$ segunda aula gravada, trabalhou-se com a leitura de acordo com as fases elencadas por Brown (2001 apud CALVO; FREITAS, 2015), sendo: pré-leitura (pre/before-reading), momento em que se ativa os conhecimentos prévios do aluno sobre o assunto; leitura (while/during-reading), para a qual elaborou-se atividades visando localização e construção do tema e compreensão global do texto; pósleitura (post/after-reading), momento em que foi promovido a expansão e análise crítica do texto. Para tanto, propôs-se uma discussão oral com os colegas sugerindo sua realização pelo WhatsApp.

\section{Resultados e discussão}

Nesta seção, aborda-se as experiências vivenciadas no estágio supervisionado, tendo como foco a habilidade oral, relacionando-a com a literatura da área. Durante a pandemia, as aulas e o estágio estão ocorrendo mediados pelas tecnologias digitais da informação e comunicação (TDIC), conforme enfatizado anteriormente. Desse modo, as aulas da rede pública de educação vêm ocorrendo de forma síncrona pela plataforma Google Meet, pela qual se encontram virtualmente alunos, docentes e aluna-

\footnotetext{
4 TED. How blue jeans were invented: Moments of Vision 10. Disponível em: https://www.youtube.com/watch?v=SCRYuUIU_Gs. Acesso em: 26 abr. 2021.

5 GAMES4ESL. Clothes Vocabulary For ESL Students: Fun Guessing Game For Kids. Disponível em: https://www.youtube.com/watch?v=PKOVLKo3Z9M. Acesso em: 28 abr. 2021.
} 
professora. Com isso, os estudantes têm a possibilidade de assistir às aulas com a câmera e o microfone desligados, fazendo participações pontuais. Logo, isso foi uma das dificuldades identificadas no desenvolvimento da produção oral do inglês, pois, ao não praticar a fala, o desenvolvimento da comunicação por meio da língua inglesa fica comprometido, o que conforme discutimos anteriormente, é preocupante, pois, segundo Corrêa (2017), gera a exclusão, uma vez que poucos deles terão a oportunidade de sanar essa lacuna fora da instituição de ensino.

Nas aulas de LI, as poucas participações dos alunos por áudio são feitas em português, e alguns com mais domínio arriscam-se a ler algum comando ou texto na LI. Nesse sentido, a docente tem o desafio de desenvolver essa habilidade engajando alunos de diferentes níveis, bem como trabalhar com a vergonha que muitos sentem. Desse modo, algumas atividades propostas por Harmer (2001 apud ALVES, 2015) poderiam ser benéficas para lidar com essa questão em sala, ou mesmo ferramentas tecnológicas que são facilmente acessadas pelo celular, como aquelas elencadas por Maria e Vieira (2020).

Nas aulas observadas, percebeu-se que a professora fazia perguntas pessoais, mais informais e interagia em português antes da aula começar, o que deixava os alunos mais animados e à vontade, sentindo-se implicados na aula. Entretanto, essa atitude resultava no uso recorrente da língua portuguesa pelos estudantes e pela docente, pois eles se cumprimentavam em português, bem como fazia as explicações do conteúdo usando a língua materna. Até mesmo a chamada era feita pela docente e respondida pelos discentes em português.

A esse respeito, considera-se que o uso da língua materna nas aulas de LE é um recurso válido para facilitar a interação entre professor e aluno, mas em excesso pode prejudicar o desenvolvimento da compreensão e produção oral do aluno na língua-alvo. Notou-se que o uso do inglês se restringia apenas aos exercícios da aula, o que demonstra um uso da língua descontextualizado, uma vez que o estudante não precisa do idioma para participar das aulas. Isso é preocupante na medida em que, conforme Rio e Nicolaides (2019), desenvolver a oralidade é algo complexo, pois envolve a utilização de diversas habilidades, como as interacionais, cognitivas, sociais, linguísticas, fisiológicas etc., e os alunos têm poucas oportunidades de praticar, a fim de aperfeiçoá-la. Dessa maneira, constata-se que, apesar da BNCC (BRASIL, 2017) defender o desenvolvimento da oralidade, a prática escolar observada durante a realização deste estágio apresenta-se bem distante do proposto pelos documentos oficiais.

A professora incluía a aluna-professora nas aulas por meio de perguntas pessoais e que estavam relacionadas ao conteúdo. Então, ela fazia as participações em inglês, e muitos alunos tinham dificuldade de compreender e interagir na língua-alvo. Isso levou a inferência de que essa habilidade também foi 
pouco enfatizada em outras aulas, o que corrobora o estudo de Corrêa (2017) sobre o pouco trabalho com a oralidade na rede regular de ensino.

Partindo do princípio que a língua é utilizada para comunicação, observa-se que faltou a docente estimular os alunos a utilizá-la mais em sala, a fim de apreenderem expressões formulaicas, que, segundo Maria e Vieira (2020), referem-se aos grupos de palavras ou frases pré-fabricadas de estrutura fixa ou semifixa, por exemplo: Hi, how's it going?; Can I help you?; See you later!; I don't really think that; I see; Oh, great! Etc. Isso é relevante na medida em que os autores enfatizam que quanto mais expressões formulaicas são memorizadas, melhor será para o desenvolvimento da fluência comunicativa do aprendiz, pois "O uso automatizado dessas fórmulas proporciona ao falante tempo para pensar em outros aspectos da produção oral como na pronúncia, entonação ou no registro mais apropriado para o contexto sociointeracional" (MARIA; VIEIRA, 2020, p. 14).

Portanto, percebeu-se que 0 trabalho com a oralidade em LI poderia ter sido inserido em mais momentos da aula, como na apresentação, despedida, conversas no chat e ao responder à chamada, isto é, palavras que são facilmente compreendidas pelos alunos e que colocam a língua como um meio de comunicação e interação com os colegas e professora. Observou-se que faltou estimular mais os discentes a usar o inglês nas aulas, seja na compreensão e produção oral, ou mesmo na escrita realizadas pelo chat.

Diante disso, a professora-estagiária, ao fazer as videoaulas, optou por usar mais a língua inglesa durante vários momentos da aula, bem como estimular a produção da oralidade em algum momento. Para tanto, ela fez perguntas aos estudantes para responderem oralmente, estimulou a repetição do vocabulário aprendido em voz alta e propôs uma discussão em pares entre os alunos por meio do WhatsApp. Mas, devido às circunstâncias causadas pela pandemia, não foi possível investigar 0 aproveitamento das atividades pelos alunos, pois as aulas foram disponibilizadas apenas como materiais complementares para seus estudos. Nesse sentido, consideramos que este foi um dos maiores desafios de realizar o estágio durante a pandemia, pois a estagiária teve pouco contato com os discentes e nenhum retorno sobre a eficácia dos materiais produzidos para a regência na prática escolar.

\section{Considerações finais}

Ao refletir sobre as experiências vividas durante a realização das atividades de estágio curricular supervisionado de LI, percebeu-se que a oralidade é pouco valorizada na sala de aula observada. Desse modo, apesar dos documentos oficiais terem sofrido alterações importantes ao longo do tempo, pouco 
se consolidou na prática da rede pública, conforme já constatado por Corrêa (2017) e Rio e Nicolaides (2019).

A esse respeito destaca-se que muitos fatores contribuem para que essa realidade venha se perpetuando, como: poucas aulas de inglês; salas numerosas, impossibilitando um trabalho mais individual com o aluno; poucas horas-atividade para os docentes prepararem bem as suas aulas e/ou (re)pensarem suas ações; falta de incentivo governamental para a formação de professores; profissionais desmotivados; entre outros motivos já elencados anteriormente. Portanto, é inegável que haverá um caminho árduo pela frente, permeado de desafios e tentativas de mudanças no ensino de línguas e para um trabalho mais efetivo com a oralidade, seja no contexto pandêmico ou não.

No que se refere ao contexto de pandemia, considera-se que, apesar das dificuldades descritas, atuar nesta modalidade propiciou aos docentes e alunos-professores conhecerem muitas ferramentas tecnológicas que permanecerão na rotina presencial. Além disso, durante a observação das aulas notouse um uso mais frequente de slides, músicas, site de atividades on-line, questionários on-line, ferramentas de gamificação, etc., o que poderão ser adaptados para a educação presencial.

Quanto à oralidade, ressalta-se que o uso de ferramentas tecnológicas pode favorecer muito a prática pedagógica, pois há aplicativos que permitem a prática da pronúncia, é possível gravar vídeos pelo celular/computador falando na língua-alvo, acompanhar e cantar a letra de uma música usando sites, produzir podcast etc. Então, apesar dos desconfortos trazidos pela pandemia, observa-se que as possibilidades para o ensino de LI foram alargadas, o que está em consonância com os apontamentos de Rio e Nicolaides (2019) sobre os benefícios das TDIC para o ensino de línguas. Entretanto, os docentes precisam conhecê-las e aproveitá-las mais em suas aulas.

Portanto, conclui-se que o estágio curricular supervisionado contribuiu muito para a formação docente, pois propiciou a atuação de alunos-professores em um contexto real de ensino, a fim de consolidar os conhecimentos teóricos na prática e entender como ocorre se dá o processo de ensino e aprendizagem de LI na educação básica pública, bem como analisar como atividades voltadas para 0 desenvolvimento da produção e compreensão oral vem sendo trabalhadas nesse contexto educacional.

\section{Referências}

ALVES, É. F. Oralidade e Ensino de Língua Estrangeira. In: ALVES, É. F. et al. (Org.) Prática Metodológica da Língua Inglesa. Eduem/Nead: Maringá, 2015.

BORGHI, C. I. B. Como aprendemos uma língua estrangeira? In: FREITAS, M. A.; CALVO, L. C. S.; BORGHI, C. I. B. Formação de professor de língua inglesa. Eduem/Nead: Maringá, 2013. 
BRASIL. Ministério da Educação. Base Nacional Curricular Comum: versão final. Secretaria da Educação Fundamental. Brasília, 2017. Disponível em: http://basenacionalcomum.mec.gov.br/abase/\#fundamental/lingua-inglesa. Acesso em: 28 maio 2020.

BRASIL. Parâmetros Curriculares Nacionais: terceiro e quarto ciclos do ensino fundamental; língua estrangeira. Brasília: Ministério da Educação, Secretaria da Educação Básica, 1998.

BRASIL. Orientações Curriculares para Ensino Médio. Linguagens, Códigos e suas Tecnologias I Secretaria da Educação Básica. Brasilia: Ministério da Educação, Secretaria da Educação Básica, 2006.

CALVO, L. C. S.; FREITAS, M. A. Foreign Language Reading. In: ALVES, É. F. (Org.). Prática Metodológica da Língua Inglesa. Eduem/Nead: Maringá, 2015.

CORREA, T. H. "To be or not to be"? Uma análise da prática da oralidade das aulas de língua inglesa nas escolas públicas brasileiras: realidade ou utopia? PERcursos Linguísticos, v. 7, n. 14, p. 295-313, 2017. Disponivel em: https://www.periodicos.ufes.br/percursos/article/view/15625. Acesso em: 11 jun. 2021.

GIMENEZ, T. et al. Inglês como língua franca: desenvolvimentos recentes. Revista Brasileira de Linguística Aplicada, Belo Horizonte, v. 15, n. 3, p. 593-619, set. 2015. https://doi.org/10.1590/1984$\underline{639820157010}$

LEFFA, V. Ensino de línguas: passado, presente e futuro. REVISTA DE ESTUDOS DA LINGUAGEM, [S.I.], v. 20, n. 2, p. 389-411, dez. 2012. https://doi.org/10.17851/2237-2083.20.2.389-411

MARIA; B. C. V.; VIEIRA, E. R. Hibridizando as aulas de língua inglesa com o Whatsapp: Caderno com sugestões para atividades de compreensão e produção oral mediadas por tecnologias digitais. 1.ed. Rio de Janeiro, 2020.2 Disponível em: https://www.cp2.g12.br/blog/mpcp2/files/2017/02/BRUNOMARIA2020PRODEDUC.pdf. Acesso em: 27 ago. 2021.

PARANÁ. Diretrizes Curriculares da Educação Básica Língua Estrangeira Moderna. Secretaria de Estado da Educação Básica do Paraná, Departamento de Educação Básica. Paraná, 2008.

RIO, M. M. O.; NICOLAIDES, C. S. Tecnologias digitais no desenvolvimento da oralidade em língua inglesa na escola pública. Revista Educar Mais, v. 3, n. 3, p. 38-45, 2019. https://doi.org/10.15536/reducarmais.3.2019.38-45.1611

VELOSO, F. S.; WALESCO, A. M. H. Estágio supervisionado remoto de línguas estrangeiras em tempos de pandemia: experiências e percepções na UFPR. Rev. Nova Paideia, Brasília/DF, v. 2, n.3. p. 35 -57, 2020. https://doi.org/10.36732/riep.v2i3.66

Data de submissão: 26/09/2021. Data de aprovação: 25/10/2021. 